https://doi.org/10.46344/JBINO.2021.v010i01.14

\title{
AGRICULTURAL INFORMATION AND COMMUNICATION SYSTEMS OF PAKISTAN
}

\section{Khalid Mehmud' and Muhammad Arshad Ullah²}

\author{
${ }^{1}$ Department of Mass Communization, Allama Iqbal Open University, Islamabad. Pakistan \\ ${ }^{2}$ Pakistan Agricultural Research Council, Islamabad. Pakistan
}

\begin{abstract}
Agriculture has a great share in Pakistan economy, but it is at the back in many aspects, characterized by deprived connectivity and breakdown of market, untrustworthy and delayed information to the farmers, small land holdings, non-adoption or less adoption of superior technology, most advantageous price of the farm produce and so on. It has become essential to discover various ways to keep farmers updated about modern technologies, technological adoption and pertinent information for good crop production to pace up in current technological era. The information technology uprising at the moment is imminent rapidly and more evident. With the foreword of information and communication technologies, the conventional agriculture has been reformed, ultimately contributing to the significant improvements in agricultural productivity and sustainability. Empowering farmers with the right information at the right time and place is essential for improving the efficiency and viability of small and marginal holdings. In Pakistan, agricultural extension and research staff is using diverse mechanisms for the dissemination of agri. information and knowledge among the farming community. Amongst these, modern information and communication tools play an important role in improving the availability of crop and market information and agricultural development.
\end{abstract}

Key Words; ICTs, Decision Support System, Widen Market Access, Kiosks and SMS 


\section{INTRODUCTION}

Agriculture sector is a huge segment of the Pakistan economy. Its contribution to Gross Domestic Product (GDP) is almost 19 per cent and absorbs around 42 percent labour force of the country (Pakistan Economic Survey, 2019-20). The augmented claim for food grains can be met only with sincere efforts in agricultural research and extension. In spite of a great share in Pakistan economy, agriculture is covering behind in many aspects, characterized by deprived connectivity and breakdown of market, untrustworthy and delayed information to the farmers, small land holdings, non-adoption or less adoption of superior technology, most advantageous price of the farm produce and so on. It has become essential to discover various ways to keep farmers updated about modern technologies, technological adoption and pertinent information for good crop production to pace up in current technological era.

The information technology uprising at the moment is imminent rapidly and more evident. With the foreword of information and communication technologies, the conventional agriculture has been reformed, ultimately contributing to the significant improvements in agricultural productivity and sustainability. Empowering farmers with the right information at the right time and place is essential for improving the efficiency and viability of small and marginal holdings (Fakhar, 2012; Pakistan Economic Survey, 2019-2020).

In Pakistan, agricultural extension and research staff is using diverse mechanisms for the dissemination of agri. information and knowledge among the farming community. Amongst these, modern information and communication tools play an important role in improving the availability of crop and market information and agricultural development particularly in developing countries (Fakhar et al., 2018).

ICTs (Information and Communication Technologies) refer to technologies that provide access to information through telecommunication medium such as the radio, television, cell phone, computers, satellite technology; internet including email, instant messaging, video conferencing and social networking websites, which have made it possible for users across the world to communicate with each other and to give users quick access to ideas and experiences from a wide range of people, communities and cultures. It further helps to enhance the agriculture productivity through better techniques in an optimal matter through cost effective

(Agrinfobank.com.pk).

Large data and information can be effectively generated, stored, analyzed, disseminated and used to upgrade agriculture by inclusion of Information (ICTs) and Communication Technology. It may increase production manifold by providing prompt, reliable and locality based information services to the farmers. Hence, ICT in agriculture has become a budding field of research and application related to e-agriculture.

In Pakistan there are more than 316 Agricultural Research Stations are working under Federal and Provincial Governments. Unluckily most part of latest 2021 January Edition | www.jbino.com | Innovative Association 
agriculture information cannot attain to the end users and vanishes within these stations.

In Pakistan only one department of Agriculture Extension is responsible to transfer the Agricultural information to the farming community and acts as a bridge between research institute \& farmers. This department is performing an excellent job by providing information to the farming community even of remote areas with their own resources. According to a research study, only one agricultural officer deals with approximately 410 farmer families in Punjab and 390 farm families in KPK respectively (Siraj, 2018).

Over the last few years rapidity of cell phone's consumption has been increased at a rapid rate and telecommunication \& IT sector reported itself as fast growing industry. According to Pakistan Telecommunication Authority (PTA), there are 8 million cell phones users in rural areas of the country. In addition to this, access of agriculture information has become more feasible after induction of $3 G$ \& $4 G$ technologies in the country (Shahbaz \& Salman, 2014).

Hence, effective utilization of ICT's has become an important tool to disseminate agricultural information to the farming community. Telecom sector can also act as a bridge between researchers and farmers and helps them in creating linkages between them for Agriculture development in the country.

Agricultural institutions were established on scientific lines by the British colonial government with the introduction of massive canal network during the beginning of 20th century. Many of the existing agricultural departments and institutions related to the irrigated agriculture in Pakistan are legacy of the colonial raj (http://www.pakissan.com/). Secretary of Agriculture was the in-charge of agriculture, animal husbandry, forestry and fisheries wings. Major institutional components of agriculture wing were Director General Agriculture in Lahore (Punjab), Peshawar (Khyber Pakhtunkhaw) and Hyderabad (Sindh) and Directorate of Agricultural Information situated in Lahore. The main protocols of Director General's are to improve area under cultivation, managing seed and fertilizer stores, supply of agricultural inputs, plant protection and training of the staff etc. The extension wing was part of the Director General. Each Director General was assisted by Director (at division level), who, in turn were supported by District officer (at District level), Deputy District Officer (at Tehsil level) and other supporting staff. Animal husbandry wing was responsible for the livestock development (disease control, animal breeding and nutrition etc.). Agricultural education in the Punjab was initiated around 1905 when Punjab Agriculture College and Research Institute was established in Lyallpur (now Faisalabad). Bureau of Agricultural Information (created in 1962) was responsible for information dissemination through print media and audio-visual aids (Slavoljub, .2014).

Since independence of Pakistan in 1947, agricultural extension services are part of the overall rural development strategies. Different extension and rural development programmes have been launched in the country to uplift the rural areas. Some of 2021 January Edition | www.jbino.com | Innovative Association 
the significant programmes include: Village Cooperative Movement, Village Agriculture and Industrial Development Programme (Village-AID), Basic Democracy System (BDS), Integrated Rural Development Programme (IRDP) and Training and Visit (T\&V) programme. Most of the researchers agree that none of these programmes were successful in long run and, hence, were abandoned one after the other (Shahbaz and Salman, 2014).

In 2001, Government of Pakistan instituted reformed of Agriculture Extension with the name 'Devolution of Power Plan', which is more advanced form of Decentralization. Under this System all extension activities are transferred at District level. Keeping in view the revolution in the telecom sector some of telecom companies launched projects for the dissemination of improved research based agricultural technology among the farmers.

\section{APPLICATIONS OF ICTS IN AGRICULTURE}

Increasing efficiency, productivity and sustainability of small scale farms, information about pest and disease control especially early warning systems, new varieties, new ways to optimize production and regulations for quality control and upto-date market information on prices for commodities, inputs and consumer trends were available to the farmers by ICT's. Further they strengthen capacities and better representation of their constituencies when negotiating input and output prices, land claims, resource rights and infrastructure projects. They also reduce social isolation, widen the perspective of local communities in terms of national or global developments, open up new business opportunities and allow easier contact with friends and relatives.

Information and Communicational Technology (IT) has many roles to perform for agricultural development starting from decision support system to the trading of crops.

ICT has a great role as decision support system to the farmers. Through ICT, farmers can be updated with the recent information about agriculture, weather, new crop varieties and new production technologies and quality measures. The dissemination of adequate, efficient and tailored technologies related to agroclimatic zone, size of farm and soil type etc. to the farmers is deficient in Pakistan's agriculture and it is the real challenge in front of policy makers in Pakistan. Information and communication technologies can broadcast the precise and authentic information at right time to the farmers so that they can utilize it and get benefits from it. The decision support system through ICT facilitates farmers for practicing good agricultural practices for cultivating, harvesting, post harvesting and marketing their produce to get better results in terms of production and pricing. One of the major drawbacks in Pakistan agriculture is complex distribution channels for marketing of agricultural produce. Farmers do not get acquainted with the updated prices of commodities, proper place for selling their inputs and consumer trends. ICT has the great potential to widen marketing horizon of farmers directly to the customers or other appropriate users for maximum benefit. Farmers may connect directly with many users and may get information about current prices for their 2021 January Edition | www.jbino.com | Innovative Association 
commodities. They can get access to the market sitting at home. Further, it will also curtail the middle man profit which will be beneficial for the farmers. This can improve a farmer's source of revenue; empower farmers for making good decisions about appropriate future crops, commodities and marketing channels to sell their produce as well as to get inputs at measurable prices.

ICT technologies can help for strengthening farming communities through wide networking and collaborations with various institutes, NGO's and private sectors. Further, farmers may enhance their own capacities through updated information and wide exposure to scientific, farming and trade.

Major components which are used in our country for providing ICT services to the farmers are web portals, mobile applications on android phone, SMS and voice messages on simple phones, information kiosks, videos and video conferencing with the experts. Agricultural experts are the key components in the whole process of disseminating information to the farmers.

The ICT components may disseminate relevant, real, customized information to the farmers at appropriate time. Hence, ICTs provide a forum to reach masses easily and to make global and local information easily accessible to the stakeholders. Information dissemination in agriculture is cost effective, time saving and speedy through ICT.

Voice messaging is an instant communication technology in which messages are transmitted via voice media. It stores voice messages in a voice mail, which can be accessed via a smart device or even a landline phone. Through this technology farmers can send their problems or ask any information to agriculture experts and get their feedback by using their cellular phones.

Mobile telephone technology has emerged as the foremost choice of the majority of the urban and rural people. Mobile phones are found as the most widely accessed tool among the farmers for communication and for accessing agriculture related information especially for the marketing of produce. Researchers also reported that mobile phones are the most used ICT tool and highly accessible by the farmers.

Kiosks is a machine which guides farmers through a text and audio mode on the various agricultural practices, land preparation, seed and seeding, fertilizer application, irrigation, plant protection measures. This technology was developed by an Indian Farmers Fertilizer Cooperative Limited after launching an application of "Agri kiosks" in 2003. This technology/machine provides a complete multilingual interface to support rural communities speaking Urdu, Punjabi, Pashto, Sindhi and Balochi.

Videos are documentaries on various topics i.e. production technologies, agriculture machinery utilization, fertilizer and insecticide applications and other cultural practices etc. In our country, Agriculture extension department plays these videos on TV Channels in national and local languages to help farmers. These documentaries are usually played on the occasions of agricultural exhibitions, fairs, farmer days and training programmes. 2021 January Edition | www.jbino.com | Innovative Association 
These documentaries are also provided to farmers / stakeholders in the form of DVD's on no profit and loss basis.

A web portal is a specially designed website that brings information from diverse sources, like emails, online forums and search engines, together in a uniform way. Some webs portals having agriculture information are being run in Pakistan.

SMS is a text messaging service component of most telephones, internet, and mobile-device systems. It uses standardized communication protocols to enable mobile devices to exchange short text messages.

A voicemail system is a computer-based system that allows users and subscribers to exchange personal voice messages; to select and deliver voice information; and to process transactions relating to individuals, organizations, products and services, using an ordinary telephone.

\section{ROLE OF ELECTRONIC MEDIA}

Various agri. radio broadcasts like "Kahit kahit haryali" and "Sandhal darti" etc. have been disseminating the agri. information to the farmers in Pakistan. In addition, the short messages regarding crops and livestock are also delivered in which information regarding agri. technologies is being provided in short time in a concise and comprehensive form. Moreover, various agencies like pesticide, fertilizer, seed, farm machinery, livestock etc. through advertisements are not only achieving the goal of promoting their products but also providing agri. information to farmers regarding their specific products.

Television is considered to be one of the effective media as a source of agricultural information for the farmers. Farmers' awareness about various telecasts may be an indicator of interest taken by them in TV telecasts. In agricultural context, various TV channels are telecasting agri. programs like "Kisan time" Channel 5; "Haryali" from PTV-Home; "Khait Punjab Day" from Punjab TV and "Apna Kisan Apni Zarait" from Apna TV etc. In addition to these programmes, short messages are also important forms of agri. TV telecasts which provide brief and comprehensive information to farmers. Advertisements relevant to agriculture are for the promotion of their products (seed, fertilizer, pesticides etc.) and at the same time act as source of agri. information for the intended audience.

The Directorate of Agri. Information Govt. of the Punjab has been playing its role in providing the farmers with the facility of audio/video cassettes and CDs about various aspects of agriculture on no profit no loss basis. Various web sites are available in Pakistan equipped with agricultural information. There are some websites having the agri. information in Urdu language like www.pakissan.com and official website of Department of Agriculture, Govt. of the Punjab www.agripunjab.gov.pk. If a farmer is internet user having the knowledge of agri websites/agri. e-mail addresses, it reflects his inclination towards using the internet as agri. information source.

Department of Agriculture, Govt. of the Punjab on its printed material related to agri. information has been mentioning official telephone Nos. enabling farmers to obtain further information pertinent to agricultural areas. Likewise, input agencies 2021 January Edition | www.jbino.com | Innovative Association 
also mention their contact Nos. on their printed material. Moreover, extension field staff on field visits or on various other occasions also gives their contact Nos. to farmers for further interaction. Farmers having awareness regarding telephone Nos. of extension field staff of public as well as private sectors are likely to use this facility for getting agricultural information.

Agri. help line is also playing an important role in answering the queries of the farming community. Directorate of Agricultural Information, Punjab has facilitated the farmers by providing them toll free agri. helpline (0800-15000 and 0800-29000) for acquiring information pertinent to their urgent and emergent issues. Telephone calls are received and feed back is given accordingly. Keeping in view the importance of livestock sector, Livestock and Dairy Development (L\&DD) Department has also extended the facility of help line (like 0800-78686) for providing livestock information to the needy farmers. Mobile companies through a unique "Kisan service" also made it easier to the farmers to keep in touch with the latest information in various spheres of agriculture like weather updates, crops, and market rates etc. Farmers can feel comforted to get the desired agri. information whenever needed. The service has been available on Mobilink as "Kisan service" and on Telenor as "Tele Kissan". This type of service has also been provided by U-fone network.

\section{ANDROID APPLICATIONS (APPS) FOR FARMERS}

An android application of Agri. Assistant was launched by the (LMKT) in collaboration of Punjab Agriculture Department on August, 2017. This mobile application enables farming community about monitoring of soil conditions in conjunction with weather forecasts to help farmers' plan for the planting and harvest season. It is the first application of its kind in Pakistan to offer farm marking on a digitalized map for real-time collection of soil samples. The application also enabled District Officer Agriculture (DOA's) to locate their assigned areas and mark farm boundaries specific to each farmer on the field maps.

An agreement was made between Telenor Pakistan and Winrock International, a leading provider of social, agriculture and environmental solutions, on October 16, 2018. The aim of this agreement was to launch a digital audio platform through which farmers could access agriculture advisories, weather updates and modern technology through their smart phones. Winrock International is being disseminated a developed content regarding information of sowing to marketing of Agriculture products and financial literacy to the farmers through Telenor's Khushaal Zamindar Digital platform. Farmers of Sindh and Punjab regions including Thatta, Mirpur Khas, Hyderabad/Matiari, Umerkot, Tando Allah Yar and Khairpur in Sindh; Shiekhupura, Multan, Muzaffargarh, Khanewal, Bahawalpur and Lodhran in Punjab are being enjoyed their services.

An application (app) exclusively dedicated to the Pakistani farmers has been launched by Jazz/Mobilink Company. The app provides necessary information relating to the agricultural needs like farming techniques, weather forecasts, cultivation methods, market rates of crops, animal husbandry, 2021 January Edition | www.jbino.com | Innovative Association 
government schemes and other agricultural news. The app is designed in Urdu language and it also uses voice response technology. The app is divided into subsections: Agricultural News, Voice recognition, Crops, Livestock, Products, Market Information, Weather Updates and Videos.

Agriculture Corner (Agricorner.com) is a social networking platform for Pakistani farmers that allow them to directly contact other farmers, extension workers, scientists and allied professionals/ institutes, irrespective of their geographic location. Agriculture Corner provides farmers an instant access to following services; Market prices, Weather forecasts, Farm advisory, News around the globe and information on livestock and dairy.

\section{Advantages of the Mobile Application}

Price Transparency: Firstly the communities are able to get the prices of major commodities including wheat, rice, maize, sugar, gur, guar seed, fruits \& vegetables from major markets like Karachi, Lahore, Faisalabad and many more.

Farm Advisory: Secondly this application sends farmers agronomic and live-stock dairy advisory both in English \& Urdu languages.

Trade Market: Thirdly trading can be carried out through this app. Trading order forwarded by the farmers will then be displayed on Agriculture Corner's web under the head of Market Trades (still in process).

Query: Fourthly Query can be generated regarding any specific issue and in response required information will be sent. In order to help agriculture extension workers for effective agricultural developments,

Punjab

Public

Management Reform Program (PPMRP) introduced an application for agricultural interventions named Agri. Smart. This application covers full scope of the Agriculture Department Extension Wing. Keeping in view the needs of Performance Monitoring System, HR module, User Tracking, Digitization of Leave Approval System, Complaint Management System, Soil Sampling, and Modification of Farmers Training Program, application is covering all these activities, Moreover this application is first ever to have checks on Quality Control of Fertilizers and keep track on Research Trails.

Fertilizer Monitoring System, Leave Application, Complaints, Extension Activities, Reporting , Pest Warning , Departmental Activities, NonDepartmental Activities, Soil Sampling, Farmer Training Programme, Feedback Forms and Research Trial application services are available.

E-Kissan Pakistan is an app for helping farmers to grow their crops with latest technology. It contains weather information and recent or hourly basis for whole of the week. It contains forecast, weather information. User/farmer can add their crops in this app by which necessary information regarding their crops like tips of the day will be provided. Farmers can also check prices of different fertilizers and pesticides.

The University of Agriculture Faisalabad has launched first agricultural mobile phone android application relating to different crops and fruits diseases, their solutions and ways to increase productivity in order to educate the farming community 2021 January Edition | www.jbino.com | Innovative Association 
Wednesday, $9^{\text {th }}$ July,2014. The Vice Chancellor was informed that initially, the application named "horticulture UAF" is covering crops and fruits including wheat, cotton and citrus.

The progressive automation of agricultural processes has significantly improved the productivity of agriculture labour, shifting masses of workers into other productive industrial areas. Since then, scientific advances in chemistry, genetics, robotics and many other applied sciences have fuelled the accelerated development of agricultural technology. In effect, in recent years agricultural production has increased substantially.

One of the latest developments in the agriculture sector, is the increase in the use of small, Unmanned Aerial Vehicles (UAVs), commonly known as drones, for agriculture. Drones are remote controlled aircraft with no human pilot on-board. These have a huge potential in agriculture in supporting evidence-based planning and in spatial data collection. Drones are used in various fields ranging from the military, humanitarian relief, disaster management to agriculture. There are a number of applications of drone technology convergence with advanced image data analytics that can be utilized in the agriculture industry. The use of drones in agriculture is extending at a brisk pace in crop production, early warning systems, disaster risk reduction, forestry, fisheries, as well as in wildlife conservation, for example. UAVs can be used in livestock management, fisheries, in surveying, land tenure, land use planning, stockpile estimation, crop damage assessment, scientific research, inspection of fixed and mobile ass etc., real estate and tourism marketing, media production, small cargo delivery, and more. Drones are used to gather a variety of image-based data about the condition of crops, fields and livestock - including: Plant height, Plant count, Plant health, Presence of nutrients, Presence of disease,

Presence of weeds, Relative biomass estimates and 3D / volumetric data (piles, patches, holes and hills). For livestock operations, drones can be used to monitor the location, status and movement of animals over time with more frequency and at a lower cost than other means

On review of the above mentioned ICT initiatives, a common framework has found to disseminate agriculture related information. Farmers are facilitated by field workers who coordinate communication between agriculture experts and farmers. However, farmers can directly access to agricultural information system. Agriculture experts are usually contacted only when required genuinely and coordinators are able to answer the queries. Use of ICT in agriculture is mainly to disseminate agriculture related information to the farmers and to trade their produce in Pakistan. The information broadcasting via online or offline but Internet is a major media require for information inflow.

The ICT initiatives in Pakistan are based mainly to disseminate information. In the current framework of ICTs, field coordinators work as a link between farmers and information system. Sometimes, farmers are unable to browse information from the system or comprehend the system. Field coordinators 2021 January Edition | www.jbino.com | Innovative Association 
may send real farm situation to the expert or information system relating to Agriculture for their advices. This framework may be improved by including more advance and high tech approach in agriculture sector. A web site of "Technology for Agriculture" available on www.atd.ztbl.com.pk was launched on November 03, 2015 to disseminate latest Agriculture information to the farmers. Farmers can receive information by using this website in following parameters:

Production technologies of different major field crops, vegetable and fruits, Brochures on crop ,

List of Progressive farmers, Case studies and Weather forecast ,Agri. Outlook (containing latest current crop, fertilizer, weather, water and market situation) ,Agri. News ,Agri. Business Supplement la compendium of latest technologies of Agriculture)

\section{LIMITATIONS IN IMPLEMENTATION OF ICTS AND POSSIBLE SOLUTIONS}

Except the great potential that ICT has in improvement of agriculture, there are some limitations that can make implementation and expansion of ICT in agricultural sector difficult. Some researches (Fakhar, 2012) explain factors and limitations preventing effective implementation and use of ICT in agricultural sector and rural areas such as: Many people in rural areas have no computer and internet access. This contributes to their lack of awareness of the benefits from using ICT. On the other side, providers of ICT and policymakers are incredulous about ability and willingness of the rural population to accept and use of ICT. As a result, there are small number of projects that improve implementation and use of ICT in agricultural sector and rural areas.

Success of strategy of ICT implementation in agriculture depends on easiness of system use by rural population. In many instances, Information Systems supporting agriculture are not easy to use and there is lack of appropriate internet information contents suitable to needs and abilities of rural population. This requires intuitive presentations based on graphics. In addition, touch screen information kiosks should be installed in order to encourage greater participation of rural population in using of ICTs. Moreover, there is a language barrier for large segments of the rural population to use systems. In order to solve this problem, commands of applications should be translated to native language and fonts for native language and mechanism for content synchronization should be installed.

Cost of computers and fees for internet access are still high for the most rural population that is poor in our country. In addition, availability of internet access is low in rural areas because Internet Service Providers (ISP) delivers services mainly in urban centers. Although great advancement is made in several past years, connectivity in rural areas should be improved. Reliable network connection is prerequisite for successful implementation of ICT in rural areas.

Even where telephone and the other communication services exist, available bandwidth can be limitation for effective use of networks. Whereas internet services for rural and agricultural areas require intensive use of graphics, low bandwidth of 2021 January Edition | www.jbino.com | Innovative Association 
network can be main limitation for providing of electronic services to farmers. Storage of static information in kiosks and transfer dynamic information from remote locations could be solution for the limitation.

Collective and coordinated efforts of many stakeholders are necessity for creation of specialized web sites and portals in agriculture. This task is so great that it cannot be done by only one institution and organization. Main stakeholders in the agricultural sector such as the fertilizer or food industries should join effort in achieving of the task.

Despite internet access, users in rural areas have to be motivated for internet use. In order to use internet, farmers and the other individuals in rural areas must have adequate level of competence and skills. Besides explained engagement of unemployed rural agricultural graduates as computer educators in rural areas, the other methods of computer literacy improvement of farmers could be used. For example, a group of farmers can install a computer with internet connection and any educated young man from that group can experience training in using computer and internet tools. He can help his colleagues to acquire computer knowledge and skills and to increase motivation to use computers and internet 1 ). Key challenge in adoption of these methods of farmers' education is to motivate young and educated people to stay in rural areas. General suggestion for governments in retaining and attracting people to rural areas is to make incentives and conditions for development of services of general interest, such as accessibility (roads, railways, waterways), ICT (broadband access, e-services, e-health, etc.), and public services (water, waste treatment, energy, health, education, etc.).

Much of potentially vital government information is not available online. Governments in many developing countries do not focus on the poor population in rural areas and do not give them appropriate information and services through internet that could be used for improvement and development of agriculture.

\section{REFERENCES}

Fakhar, I. 2012. An evaluation of Farmers Field School in dissemination of improved Agriculture Technology among the Farmers. M.Sc.(Hons.)Thesis, Agric. Ext., Arid Agriculture University Rawalpindi, Pakistan.

Fakhar, I., Awais. A, B. N. Siddiqui and Khalid. M. C. 2018. Role of ICT's in Agricultural Development: A Case Study from Jazz Ba-Khaber Kissan Service. The International Journal Of Humanities \& Social Studies. 6: 5 (275-280).

http://agrinfobank.com.pk/10-bestagriculture-website-for-farmers-in-pakistan/ https://www.Imkt.com/Imkt-to-launch-agriassistant-mobile-application-for-improvingfarmer-welfare-in-punjab/

https://play.google.com/store/apps/detail $s$ ? id=pk.gov.pitb.agrismart\&hl=en_US

http://www.pakissan.com/english/news/ne wsDetail.php? newsid $=26722$ Pakistan Economic Survey, 2019-20. Government of Pakistan. 
Siraj. M. (2018) Model for ICT based services for agriculture extension in Pakistan.Book available at www.cabi.org.

Shahbaz B. and Salman A. 2014. Agricultural Extension Services in Pakistan: Challenges, Constraints and Ways forward. Research Gate. UAF. Faislabad

Slavoljub M., .2014.The Role and Potential of Information Technology in Agricultural Improvement Economics of Agriculture 2/2014 UDC: 004.738.5:631 Review Article

http://www.agricorner.com/agriculturecorner-launches-mobile-app-for-farmers/

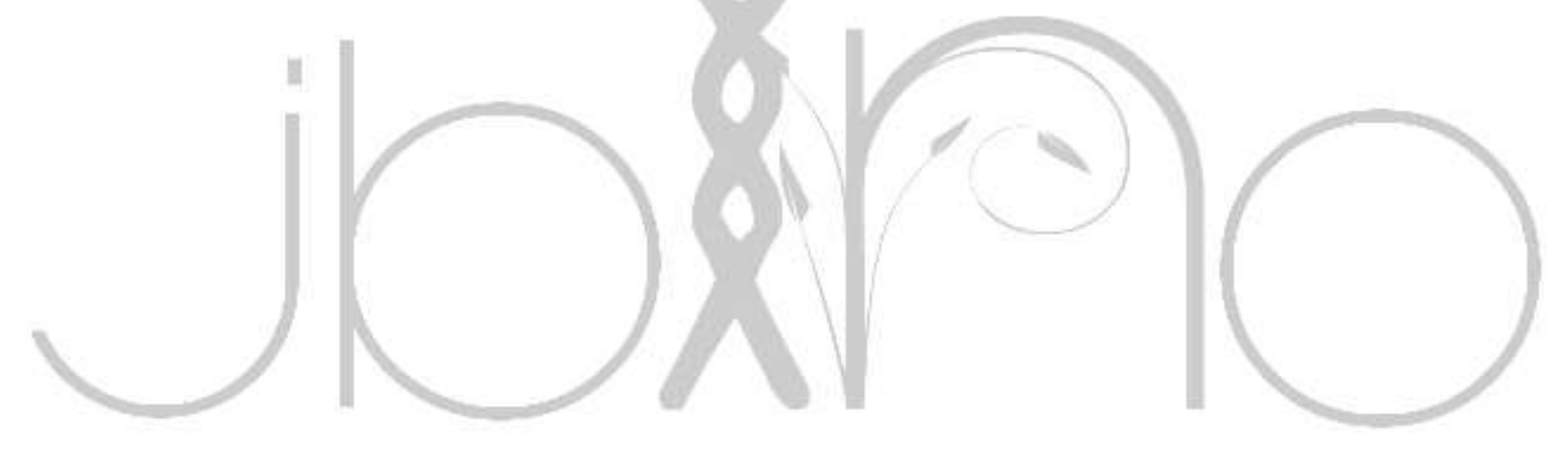

